\title{
RESEARCH
}

Open Access

\section{Does low income effects 5-year mortality of hepatocellular carcinoma patients?}

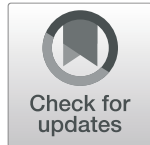

Dong Jun Kim ${ }^{1,2 \dagger}{ }^{+}$, Ji Won Yoo ${ }^{3 \dagger}$, Jong Wha Chang ${ }^{4}$, Takashi Yamashita ${ }^{5}$, Eun-Cheol Park ${ }^{6,7}$, Kyu-Tae Han ${ }^{8}$, Seung Ju Kim ${ }^{9}$ and Sun Jung Kim ${ }^{2,10,11^{*}}$ (D)

\begin{abstract}
Background: In Korea, the universal health system offers coverage to all members of society. Despite this, it is unclear whether risk of death from hepatocellular carcinoma (HCC) varies depending on income. We evaluated the impact of low income on HCC mortality.

Methods: The Korean National Health Insurance sampling cohort was used to identify new HCC cases $(n=7325)$ diagnosed between 2004 and 2008, and the Korean Community Health Survey data were used to investigate community-level effects. The main outcome was 5-year all-cause mortality risk, and Cox proportional hazard models were applied to investigate the individual- and community-level factors associated with the survival probability of HCC patients.

Results: From 2004 to 2008, there were 4658 new HCC cases among males and 2667 new cases among females. The 5-year survival proportion of males was $68 \%$, and the incidence per person-year was 0.768 ; the female survival proportion was 78\%, and the incidence per person-year was 0.819. Lower income was associated with higher hazard ratio (HR), and HCC patients with hepatitis B (HBV), alcoholic liver cirrhosis, and other types of liver cirrhosis had higher HRs than those without these conditions. Subgroup analyses showed that middle-aged men were most vulnerable to the effects of low income on 5-year mortality, and community-level characteristics were associated with survival of HCC patients.

Conclusion: Having a low income significantly affected the overall 5-year mortality of Korean adults who were newly diagnosed with HCC from 2004 to 2008. Middle-aged men were the most vulnerable. We believe our findings will be useful to healthcare policymakers in Korea as well as to healthcare leaders in countries with $\mathrm{NHI}$ programs who need to make important decisions about allocation of limited healthcare resources according to a consensually accepted and rational framework.
\end{abstract}

Keywords: Hepatocellular carcinoma, Liver Cancer, Low income, Mortality, Multi-level analysis, Cox proportional hazard model

\footnotetext{
* Correspondence: sunjkim0623@sch.ac.kr

${ }^{\dagger}$ Dong Jun Kim and Ji Won Yoo contributed equally to this work.

${ }^{2}$ Center for Healthcare Management Science, Soonchunhyang University,

Asan, Republic of Korea

${ }^{10}$ Department of Health Administration and Management, College of Medical

Science, Soonchunhyang University, 22 Soonchunhyang-ro, Asan 31538,

Republic of Korea

Full list of author information is available at the end of the article
}

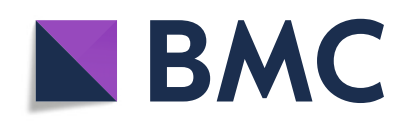

() The Author(s). 2021 Open Access This article is licensed under a Creative Commons Attribution 4.0 International License, which permits use, sharing, adaptation, distribution and reproduction in any medium or format, as long as you give appropriate credit to the original author(s) and the source, provide a link to the Creative Commons licence, and indicate if changes were made. The images or other third party material in this article are included in the article's Creative Commons licence, unless indicated otherwise in a credit line to the material. If material is not included in the article's Creative Commons licence and your intended use is not permitted by statutory regulation or exceeds the permitted use, you will need to obtain permission directly from the copyright holder. To view a copy of this licence, visit http://creativecommons.org/licenses/by/4.0/. The Creative Commons Public Domain Dedication waiver (http://creativecommons.org/publicdomain/zero/1.0/) applies to the data made available in this article, unless otherwise stated in a credit line to the data. 


\section{Background}

Mortality rates due to hepatocellular carcinoma (HCC) have tended to increase in many countries in recent decades [1]. In 2018, HCC was the second most common cause of cancer-related mortality in Korea, with a rate of 20.7 per 100,000 [2], which is two- to five-fold higher than in most European countries and the United States [1]. The Korean government has implemented many cancer management policies to identify and resolve these HCC problems [3]. However, the results of the policy were not equal among all HCC patients in Korea [4].

In Korea, HCC is the most common cause of cancer mortality in men aged 40-59 [3]. The consequent economic loss in this age group was estimated to be US $\$ 2.8$ billion in 2014, which is the largest economic deficit associated with any type of cancer in Korea [3]. Individuallevel biological and contextual factors, such as economic conditions, can affect HCC mortality rates $[5,6]$. Low income, which is usually defined as the bottom $20 \%$ of the income distribution in a country [7], can increase the risk for mortality in HCC patients [5, 6]. Low income is linked to barriers to both formal and informal access to overall healthcare and, in turn, to HCC treatment [8]. Although there have been no nationwide studies on the effects of income on HCC mortality under the universal health system, a study of Ontario [9] residents showed that HCC patients in the lowest income quintile had a $10 \%$ higher HCC-related mortality rate than other groups [9].

In terms of socioeconomic factors, access to health insurance is a key factor that enables patients to benefit from the most current treatments [10]. In Korea, under the universal health system, health insurance coverage applies to all members of society. However, individual income is another factor that enables access to health care because, in 2015, the mandatory public health insurance covered only $64 \%$ of all healthcare expenditures, leaving $36 \%$ of these expenditures to be paid by private supplementary insurance or individuals [7]. Uncovered services included surcharges for specialists at general hospitals, new and high-cost diagnostic or therapeutic services, and private wards [11]. Standard coverage by the National Health Insurance (NHI) can be insufficient for Korean households in general and low-income adults in particular [12]. To increase the financial protection available in the event of catastrophic illness, the Korean government expanded the NHI coverage for cancer patients in 2005; however, the gap between the benefits available to low- and high-income cancer patients remains unchanged [11, 12].

Furthermore, although a few studies have examined the occurrence of and survival following diagnoses of breast, prostate, and colorectal cancer as a function of regional socioeconomic status (SES) [13-16], there has been no comparable HCC-related research. This study investigated the association between low income and HCC mortality at the national level in Korea in the context of community characteristics. We also evaluated whether this association differed by age and sex and estimated the HCC-related mortality risks associated with individual-level demographic characteristics.

\section{Methods \\ Study population}

We used data from the Korean National Health Insurance Service-National Sampling Cohort (NHIS-NSC), which was collected based on a systematic sampling design in 2002-2013, to produce a nationally representative random sample of 1,025,340 individuals, as well as the 2008 Korea Community Health Survey (KCHS) involving data on 200,000 individuals obtained from 253 community health centers $[17,18]$. To investigate the associations between individual- and community-level characteristics and survival of HCC patients, we first identified individuals diagnosed with HCC between 2002 and 2013 according to the International Classification of Diseases, version 10 (ICD-10): C22. Then we excluded patients diagnosed during 2002-2003 to ensure that our sample was restricted to newly diagnosed HCC cases under the assumption that, if an individual had no HCC diagnosis in the entire two-year period, then the first diagnosis of HCC from 2004 onward was new. This is because the first diagnosis should be distinguished, taking into account the long disease cycle of cancer. We also excluded patients diagnosed with HCC during 2009-2013 to further restrict the sample to only patients who were followed for 60 months because it is impossible to track the censoring that occurs during this period; this criterion covered patients who were diagnosed during 2004-2008. Then we transposed the dataset into a retrospective cohort design in which the unit of analysis was information from each HCC patient. These claims data consist of a single case of patient medical use. We summarized each case into one patient episode. After that, survival time was measured from the first diagnosis to the time of death, and patients who did not die were defined as survival. To evaluate each HCC patient's community-level characteristics, we summarized each municipality's characteristics from individuals of the KCHS, conducted by the Korean Center for Disease Control and Prevention [17, 18]. Furthermore, we matched individual- and community-level data and obtained data on the characteristics of 7325 new HCC patients and their respective 238 municipalities (Fig. 1). This study was reviewed and approved by the Institutional Review Board of Soonchunhyang University (2017-05-BM-014). 


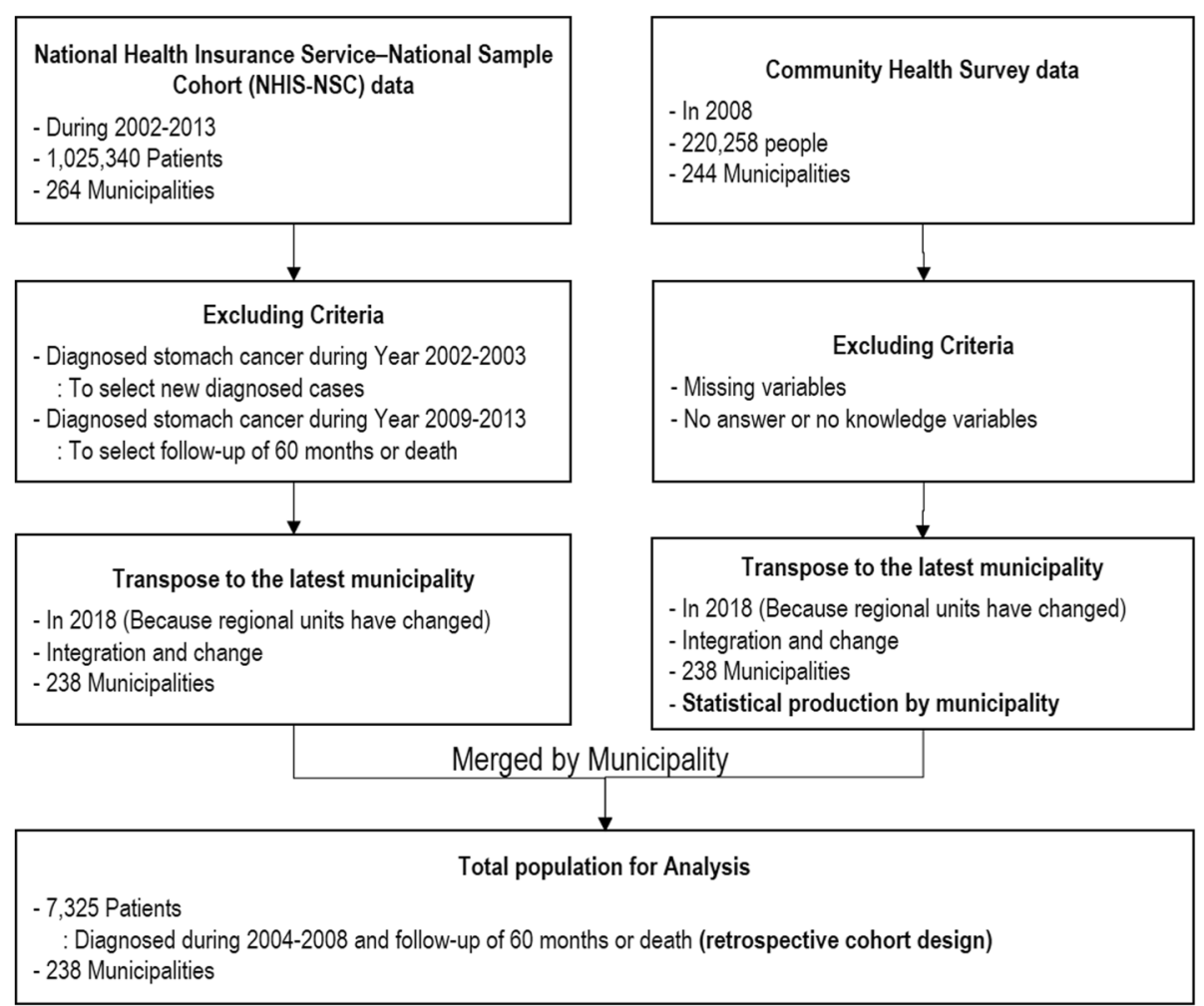

Fig. 1 Flowchart of sample selection process

\section{Variables}

The main outcomes were number of deaths and survival time from HCC over the course of a 5-year follow-up period. The index date was defined as the date of diagnosis. All-cause death data were included in the dataset; however, cause of death could not be identified. Individual-level variables were sex, year of HCC diagnosis, HCC etiology, patient age, income, and disability at diagnosis of HCC. Patient ages were categorized into the following groups (in years): 49 or younger, 50-59, 6069 , and 70 or older. We categorized income into NHI contribution quintiles: 1st quintile (20th or lower percentiles), 2nd quintile (21st-40th percentiles), 3rd quintile (41st-60th percentiles), 4th quintile (61st-80th percentiles), and 5th quintile (80th or higher percentiles) $[17,19]$. Data on the status (physical disability or allcause disability) and severity (grade 1 or 2 , severe; grade $3-6$, mild) of the disability were provided by the NHISNSC based on evaluations performed by the treating physician according to the specific guidelines established by the Korean government [17, 18]. The etiologies of HCC were defined as follows based on ICD-10 coding: $\mathrm{HBV}$, hepatitis c (HCV), alcoholic liver cirrhosis, and other (non-viral non-alcoholic) liver cirrhosis. The KCHS analyzed the following community-level variables in 2008: current smoking rate, high-risk drinking rate, percentage of residents who walk for exercise, obesity rate, and percentage of college graduates. The current smoking rate was defined as the percentage of people who had smoked more than five packs (100 cigarettes) in their lifetime and who were currently smoking (smoked "daily" or "sometimes"). High-risk drinking was defined as consuming seven or more (men) or five or more (women) alcoholic drinks on the same occasion on at least 2 days within the past 7 days. The percentage of residents who walked for exercise was the percentage of people who had walked more than 30 min per day during the last week (7 days). The obesity rate was defined as percentage of people with a body mass index (BMI; $\mathrm{kg} / \mathrm{m}^{2}$ ) greater than 25.

\section{Statistical analyses}

We first examined the number and characteristics of individuals newly diagnosed with HCC during the 5-year study period. The frequencies and relative percentages were calculated for categorical variables, and $x^{2}$ tests were performed to examine differences in each variable by survival. The incidence per person-years and followup period were examined as a function of patient characteristics. Also, according to income level, the distribution of deaths and the person-years at deaths were calculated for each variable, and a $\chi^{2}$ test was conducted on the distribution. To investigate associations between patient characteristics and death from HCC, after testing 
the proportionality assumptions by the Grambsch and Therneau non-proportionality test and $\log (-\log \{\mathrm{S}(\mathrm{t})\})$ plot, we used Cox proportional hazard models to estimate hazard ratios (HRs) and corresponding 95\% confidence intervals (CIs). To identify the individual and community factors associated with the survival probability of HCC patients, we employed a multi-level survival model to include regional-level random effects in an individual model. In addition, subgroup analyses were performed by sex and age groups, trend analysis was performed according to decrease in income level by model, and the threshold for statistical significance was set at $p<0.05$ (two-tailed) for all analyses. All statistical analyses were performed using SAS statistical software, version 9.4 (SAS Institute Inc., Cary, NC, USA).

\section{Results}

\section{Patients and characteristics}

Table 1 presents patient characteristics, number of deaths, and mean survival times. The number of new HCC cases from 2004 to 2008 was stable, with 4658 cases among males and 2667 cases among females. The 5 -year survival proportion of males was $68 \%$, and the incidence per person-year was 0.768 ; the female survival proportion was $78 \%$, and the incidence per person-year was 0.819 . The mortality proportion of the highest income group was $25 \%$, while those of the 4 th, 3rd, 2nd, and 1 st quintiles were $26,28,31$, and $35 \%$, respectively $(p<0.001)$. Patients with liver cirrhosis had higher mortality rates and shorter survival times than patients without cirrhosis, but an inverse association was found for patients with HBV or HCV. Table 2 shows death information by income level. Table 2 presents, according to income level, the distribution of deaths and the personyears (PY) at deaths. There was a difference in the proportion of deaths and the person-years according to income group (1st quintile: the proportion $=67.2 \%$, PY $=$ 0.670 ; 2nd quintile: the proportion $=62.2 \%, \mathrm{PY}=0.669$; 3rd quintile: the proportion $=66.9 \%, \mathrm{PY}=0.852$; 4th quintile: the proportion $=62.8 \%, \mathrm{PY}=0.725$; 5 th quintile: the proportion $=60.9 \%, \mathrm{PY}=0.727$ ).

\section{Risk factors associated with mortality in HCC}

Table 3 shows the hazard ratios of patients with HCC according to both Cox proportional hazard models after adjusting for all other covariates. The HRs of HCC patients increased with age and lower income $(p<0.001)$. However, there were no significant differences between those in the 4th and 5th quintiles of income $(p=0.161)$. Furthermore, HCC patients with HBV, alcoholic liver cirrhosis, and other types of liver cirrhosis had higher HRs than those without these conditions (HBV: HRs = 1.172, $p=0.001$; alcoholic liver cirrhosis: HRs $=2.187$, $p<0.001$; other liver cirrhosis: HRs $=1.214 p=0.023$ ), but the opposite pattern was found with regard to $\mathrm{HCV}$ $(\mathrm{HRs}=0.812, p<0.001)$. The consequences of community factors indicated that higher current smoking rates and a greater percentage of college graduates in the community were associated with higher HRs, and that walking for exercise was associated with lower HRs among HCC patients.

\section{Subgroup analyses: HCC mortality by sex and age}

Table 4 presents the results of multilevel multivariate analyses of HCC mortality by sex and age. Among male HCC patients, there was a difference in hazard ratio according to income group (1st quintile: $\mathrm{HR}=1.422, p<$ 0.001; 2nd quintile: $\mathrm{HR}=1.560, p<0.001$; 3rd quintile: $\mathrm{HR}=1.422, p<0.001$; reference group, 5th quintile). Among HCC patients aged 50-59, there was a difference in hazard ratio according to income group (4th quintile: $\mathrm{HR}=1.509, p=0.010$; 3rd quintile: $\mathrm{HR}=1.593, p=0.005$; 2nd quintile: $\mathrm{HR}=2.089, p<0.001$; 1st quintile: $\mathrm{HR}=$ $2.197, p<0.001$; reference group, 5th quintile), and a significant association also was found in those aged 49 years or younger and 60-69. However, there was no such association among women or those aged 70 years or older who had been diagnosed with HCC.

Table 5 presents the adjusted HRs of HCC mortality for the lowest (1st quintile) and highest (5th quintile, reference) income groups by sex and age considering group interactions. Among male patients, the lowest income group was associated with an increased risk for HCC mortality compared to the highest income group among patients $50-59$ years and 49 years or younger $(\mathrm{HR}=1.956, p<.001$ for 49 or younger; $\mathrm{HR}=2.678$, $p<.00150-59$ years). No such association was observed among middle aged female patients $(p=0.151$ for 49 or younger; $p=0.73450-59$ years).

\section{Discussion}

Having a low income significantly affected the overall 5year mortality of Korean adults newly diagnosed with HCC from 2004 to 2008. Middle-aged men with HCC were more vulnerable to the effects of low income on 5year mortality than were younger and older men and compared to women of all ages.

Our results are similar to those of previous research on the association between health outcomes and SES among HCC patients [20-22]. Although it is difficult to compare health outcomes across health systems, HCC patients living in economically deprived areas in the U.S. are more likely to be diagnosed at an earlier age [20], and those living in the U.K. have a shorter life expectancy [21]. According to nationally representative U.S. cancer registry data, health insurance type (uninsured and Medicaid) and living in low-income communities are associated with worse health outcomes in HCC 
Table 1 Patient characteristics, number of deaths, and mean survival periods

\begin{tabular}{|c|c|c|c|c|c|c|}
\hline Variables & N/Mean & $\% / S D$ & Number of deaths & $\%$ & $p^{*}$ & $\begin{array}{l}\text { Incidence } \\
\text { per person-years }\end{array}$ \\
\hline \multicolumn{7}{|l|}{ Sex } \\
\hline Male & 4658 & 63.6 & 1491 & $32 \%$ & \multirow[t]{2}{*}{$<.001$} & 0.768 \\
\hline Female & 2667 & 36.4 & 576 & $22 \%$ & & 0.819 \\
\hline \multicolumn{7}{|l|}{ Age group } \\
\hline 49 or younger & 2903 & 39.6 & 391 & $13 \%$ & \multirow[t]{4}{*}{$<.001$} & 0.726 \\
\hline $50-59$ & 1772 & 24.2 & 395 & $22 \%$ & & 0.704 \\
\hline $60-69$ & 1574 & 21.5 & 600 & $38 \%$ & & 0.769 \\
\hline 70 or older & 1076 & 14.7 & 681 & $63 \%$ & & 0.888 \\
\hline \multicolumn{7}{|l|}{ Income (quintiles) } \\
\hline The 5th (highest) & 2197 & 30.0 & 549 & $25 \%$ & \multirow[t]{5}{*}{$<.001$} & 0.810 \\
\hline The 4th & 1649 & 22.5 & 429 & $26 \%$ & & 0.720 \\
\hline The 3rd & 1310 & 17.9 & 371 & $28 \%$ & & 0.774 \\
\hline The 2nd & 1083 & 14.8 & 339 & $31 \%$ & & 0.821 \\
\hline The 1st (lowest) & 1086 & 14.8 & 379 & $35 \%$ & & 0.789 \\
\hline \multicolumn{7}{|l|}{ Disability } \\
\hline None & 6751 & 92.2 & 1824 & $27 \%$ & \multirow[t]{3}{*}{$<.001$} & 0.791 \\
\hline Mild & 459 & 6.3 & 189 & $41 \%$ & & 0.725 \\
\hline Severe & 115 & 1.6 & 54 & $47 \%$ & & 0.673 \\
\hline \multicolumn{7}{|l|}{ New cases by year } \\
\hline 2004 & 1478 & 20.2 & 450 & $30 \%$ & \multirow[t]{5}{*}{0.033} & 0.822 \\
\hline 2005 & 1493 & 20.4 & 433 & $29 \%$ & & 0.776 \\
\hline 2006 & 1324 & 18.1 & 387 & $29 \%$ & & 0.773 \\
\hline 2007 & 1352 & 18.5 & 362 & $27 \%$ & & 0.819 \\
\hline 2008 & 1678 & 22.9 & 435 & $26 \%$ & & 0.727 \\
\hline \multicolumn{7}{|l|}{ Hepatitis B } \\
\hline No & 4749 & 64.8 & 1397 & $29 \%$ & \multirow[t]{2}{*}{0.002} & 0.822 \\
\hline Yes & 2576 & 35.2 & 670 & $26 \%$ & & 0.708 \\
\hline \multicolumn{7}{|l|}{ Hepatitis C } \\
\hline No & 5897 & 82.2 & 1730 & $29 \%$ & \multirow[t]{2}{*}{0.036} & 0.815 \\
\hline Yes & 1304 & 17.8 & 337 & $26 \%$ & & 0.643 \\
\hline \multicolumn{7}{|l|}{ Alcoholic liver cirrhosis } \\
\hline No & 6820 & 93.1 & 1786 & $26 \%$ & \multirow[t]{2}{*}{$<.001$} & 0.810 \\
\hline Yes & 505 & 6.9 & 281 & $56 \%$ & & 0.637 \\
\hline \multicolumn{7}{|c|}{ Other (non-viral, non-alcoholic) liver cirrhosis } \\
\hline No & 6895 & 94.1 & 1901 & $28 \%$ & \multirow[t]{2}{*}{$<.001$} & 0.801 \\
\hline Yes & 430 & 5.9 & 166 & $39 \%$ & & 0.610 \\
\hline \multicolumn{7}{|l|}{ Regional Level } \\
\hline Current smoking rate $^{\dagger}$ & 23.6 & 3.0 & & & & \\
\hline High-risk drinking rate $^{\dagger}$ & 16.4 & 3.7 & & & & \\
\hline Walking exercise practice rate ${ }^{+}$ & 51.8 & 12.2 & & & & \\
\hline Obesity rate $^{\dagger}$ & 21.5 & 2.9 & & & & \\
\hline Percentage of college graduates ${ }^{\dagger}$ & 34.2 & 12.6 & & & & \\
\hline
\end{tabular}


Table 2 The proportion and survival time according to income of the death

\begin{tabular}{|c|c|c|c|c|c|c|c|c|c|c|c|}
\hline \multirow[t]{3}{*}{ Variables } & \multicolumn{11}{|c|}{ Income (quintiles) } \\
\hline & \multicolumn{2}{|c|}{ The 1st (lowest) } & \multicolumn{2}{|c|}{ The 2nd } & \multicolumn{2}{|c|}{ The 3rd } & \multicolumn{2}{|c|}{ The 4th } & \multicolumn{2}{|c|}{ The 5th (highest) } & \multirow[t]{2}{*}{$p^{*}$} \\
\hline & $\%$ & PY † & $\%$ & $\mathrm{PY}^{\dagger}$ & $\%$ & $\mathrm{PY}^{\dagger}$ & $\%$ & $\mathrm{PY}^{\dagger}$ & $\%$ & $\mathrm{PY}^{\dagger}$ & \\
\hline \multicolumn{12}{|l|}{ Sex } \\
\hline Male & 39.4 & 0.763 & 37.0 & 0.853 & 33.4 & 0.776 & 29.8 & 0.703 & 26.8 & 0.772 & \multirow[t]{2}{*}{0.094} \\
\hline Female & 27.8 & 0.854 & 20.8 & 0.729 & 19.4 & 0.769 & 18.8 & 0.779 & 22.0 & 0.898 & \\
\hline \multicolumn{12}{|l|}{ Age group } \\
\hline 49 or younger & 18.2 & 0.963 & 17.6 & 0.975 & 14.6 & 0.851 & 12.0 & 0.731 & 9.6 & 0.935 & \multirow[t]{4}{*}{$<.001$} \\
\hline 9 & 29.1 & 0.781 & 28.3 & 0.908 & 22.4 & 0.674 & 22.7 & 0.770 & 15.5 & 0.774 & \\
\hline $60-69$ & 41.8 & 0.701 & 41.1 & 0.760 & 45.2 & 0.801 & 36.1 & 0.639 & 31.6 & 0.662 & \\
\hline 70 or older & 67.2 & 0.670 & 62.2 & 0.669 & 66.9 & 0.852 & 62.8 & 0.725 & 60.9 & 0.727 & \\
\hline \multicolumn{12}{|l|}{ Disability } \\
\hline None & 33.6 & 0.820 & 30.2 & 0.823 & 27.0 & 0.767 & 25.0 & 0.736 & 23.9 & 0.819 & \multirow[t]{3}{*}{$<.001$} \\
\hline Mild & 44.8 & 0.747 & 40.8 & 0.742 & 41.4 & 0.761 & 38.1 & 0.611 & 41.0 & 0.792 & \\
\hline Severe & 44.8 & 0.453 & 52.6 & 1.039 & 59.1 & 1.088 & 36.4 & 0.647 & 43.5 & 0.568 & \\
\hline \multicolumn{12}{|l|}{ New cases by year } \\
\hline 2004 & 37.2 & 0.816 & 28.1 & 0.765 & 34.9 & 0.697 & 28.9 & 0.907 & 27.2 & 0.899 & \multirow[t]{5}{*}{0.002} \\
\hline 2005 & 39.2 & 0.687 & 34.0 & 0.947 & 29.7 & 0.828 & 25.7 & 0.745 & 23.9 & 0.729 & \\
\hline 2006 & 35.6 & 0.925 & 35.5 & 0.883 & 28.1 & 0.732 & 28.7 & 0.618 & 24.8 & 0.839 & \\
\hline 2007 & 30.7 & 0.911 & 33.0 & 0.734 & 27.6 & 0.944 & 22.1 & 0.635 & 24.5 & 0.921 & \\
\hline 2008 & 33.0 & 0.729 & 26.3 & 0.774 & 22.8 & 0.725 & 24.4 & 0.720 & 24.4 & 0.708 & \\
\hline \multicolumn{12}{|l|}{ Hepatitis B } \\
\hline No & 36.1 & 0.851 & 30.9 & 0.826 & 28.8 & 0.820 & 27.9 & 0.729 & 26.9 & 0.885 & \multirow[t]{2}{*}{0.426} \\
\hline Yes & 32.7 & 0.686 & 32.1 & 0.810 & 27.4 & 0.700 & 22.8 & 0.702 & 21.4 & 0.672 & \\
\hline \multicolumn{12}{|l|}{ Hepatitis C } \\
\hline No & 35.4 & 0.818 & 31.0 & 0.916 & 28.4 & 0.813 & 27.0 & 0.729 & 25.7 & 0.837 & \multirow[t]{2}{*}{0.355} \\
\hline Yes & 32.4 & 0.658 & 32.8 & 0.553 & 27.9 & 0.639 & 21.7 & 0.680 & 21.6 & 0.686 & \\
\hline \multicolumn{12}{|c|}{ Alcoholic liver cirrhosis } \\
\hline No & 32.3 & 0.854 & 28.3 & 0.860 & 25.6 & 0.782 & 24.0 & 0.737 & 24.2 & 0.834 & \multirow[t]{2}{*}{$<.001$} \\
\hline Yes & 62.1 & 0.560 & 63.7 & 0.671 & 56.6 & 0.740 & 51.6 & 0.638 & 44.0 & 0.579 & \\
\hline \multicolumn{12}{|c|}{ Other (non-viral, non-alcoholic) liver cirrhosis } \\
\hline No & 33.6 & 0.809 & 30.6 & 0.831 & 27.7 & 0.803 & 25.6 & 0.751 & 24.5 & 0.818 & \multirow[t]{2}{*}{0.420} \\
\hline Yes & 53.6 & 0.643 & 42.9 & 0.715 & 37.5 & 0.551 & 32.1 & 0.491 & 33.9 & 0.715 & \\
\hline
\end{tabular}

${ }^{*}$ Chisq-test,${ }^{\dagger}$ Incidence per person-years

patients [23]. The importance of monitoring and screening populations at risk for $\mathrm{HCC}$, particularly young adults with HBV and/or intravenous drug users, cannot be stressed enough. Economic deprivation and poor access to healthcare likely result in a greater risk for HCC and a shorter survival time. Moreover, among U.S. adults with chronic liver disease (CLD), low income contributed to an increased risk for liver-related mortality [24].

Sudden loss of wealth or a home has been shown to constitute major psychological stressors among U.S. adults [25-27]. Low-income adults with HCC might not be able to afford surcharged services, such as specialty doctors at general hospitals and new and high-cost technology; they also might show lower adherence to prescribed medication regimens and delay needed medical care during the early stages of HCC beyond the NHI coverage deadline $[8,27]$. In other words, due to the possible burden of high out-of-pocket expenses, lowincome HCC patients might not be able to benefit from new and high-cost diagnostic and therapeutic technology that is not covered by the NHI $[11,12]$. The effects of low income on HCC mortality can extend to nonmedical domains, particularly among middle-aged adults. Indeed, during the Great Recession of the late 2000 s in the U.S., non-medical social welfare spending 
Table 3 Adjusted hazard ratios of hepatocellular carcinoma mortality by multi-level

\begin{tabular}{|c|c|c|}
\hline Variables & HR(Hazard Ratio) & $p$-value \\
\hline \multicolumn{3}{|l|}{ Sex } \\
\hline Female & Reference & \\
\hline Male & 1.694 & $<.001$ \\
\hline \multicolumn{3}{|l|}{ Age group } \\
\hline 49 or younger & Reference & \\
\hline $50-59$ & 1.691 & $<.001$ \\
\hline $60-69$ & 3.338 & $<.001$ \\
\hline 70 or older & 8.267 & $<.001$ \\
\hline \multicolumn{3}{|l|}{ Income (quintiles) } \\
\hline The 5th (highest) & Reference & \\
\hline The 4th & 1.096 & 0.161 \\
\hline The 3rd & 1.323 & $<.001$ \\
\hline The 2nd & 1.414 & $<.001$ \\
\hline The 1st (lowest) & 1.451 & $<.001$ \\
\hline \multicolumn{3}{|l|}{ Disability } \\
\hline None & Reference & \\
\hline Mild & 1.144 & 0.084 \\
\hline Severe & 1.454 & 0.008 \\
\hline \multicolumn{3}{|l|}{ New cases by year } \\
\hline 2004 & Reference & \\
\hline 2005 & 0.949 & 0.441 \\
\hline 2006 & 1.030 & 0.675 \\
\hline 2007 & 0.933 & 0.336 \\
\hline 2008 & 0.914 & 0.192 \\
\hline \multicolumn{3}{|l|}{ Hepatitis B } \\
\hline No & Reference & \\
\hline Yes & 1.172 & 0.001 \\
\hline \multicolumn{3}{|l|}{ Hepatitis C } \\
\hline No & Reference & \\
\hline Yes & 0.812 & $<.001$ \\
\hline \multicolumn{3}{|l|}{ Alcoholic liver cirrhosis } \\
\hline No & Reference & \\
\hline Yes & 2.187 & $<.001$ \\
\hline \multicolumn{3}{|c|}{ Other (non-viral, non-alcoholic) liver cirrhosis } \\
\hline No & Reference & \\
\hline Yes & 1.214 & 0.023 \\
\hline \multicolumn{3}{|l|}{ Regional Level } \\
\hline Current smoking rate* & 1.019 & 0.038 \\
\hline High-risk drinking rate* & 0.994 & 0.331 \\
\hline Walking exercise practice rate * & 0.996 & 0.037 \\
\hline Obesity rate * & 1.003 & 0.634 \\
\hline Percentage of college graduates * & 1.005 & 0.023 \\
\hline Income $^{\dagger}$ & 1.106 & $<.001$ \\
\hline
\end{tabular}

${ }^{*}$ Continuous variable at regional level ${ }^{\dagger}$ Trend test according to decrease in income level provided a social safety net for middle-aged individuals, who generally make larger economic contributions but receive fewer welfare benefits compared to older individuals [28]. The effects of low income on HCC mortality often decrease in later life because of the increased availability of social welfare programs and access to health care with lower amounts of out-of-pocket expenses observed in older individuals [1, 3, 29]. Health behaviors are plausible mediators of health disparities because of social patterning and these influences on health outcomes [30]. Among socially disadvantaged individuals, for example, low-income individuals are prone to be more influenced by sudden loss of wealth or a home, perception of fewer benefits of health behaviors, and pessimistic attitudes of later life [30].

This study had several limitations, and caution is required when interpreting the results and attempting to generalize its findings. Although we analyzed all nationwide inpatient claims for HCC during a defined period, Korea's unique healthcare delivery and insurance system might significantly limit generalizability of the results to other nations. In addition, given the nature of the health insurance claims dataset, this study retrospectively calculated the time of diagnosis of HCC patients. Although we used the diagnostic information in the claims data, we are confident that the time of diagnosis used in this study reflects the time of actual diagnosis of HCC patients because we reviewed the claims in all available years and excluded the first 2 years of data. However, some degree of measurement error due to unavailability of data on the actual time of diagnosis was unavoidable. Therefore, additional research using cohort data should be performed to verify the associations examined in this study. In addition, potentially important clinical information was not available. For example, we were not able to access the detailed clinical information on HCC patients contained in the health insurance claims data collected by the National Cancer Center. Although we included duration from diagnosis to death or end of follow up in the analytic models, additional clinical information would have improved the validity of our findings. Additional information, such as cancer stage, site of cancer, and type of cancer, should be considered in future studies to build on our findings and calibrate estimates of the survival probability of HCC patients. In addition, detailed individual- and community-level information on SES was not available for our analyses. For example, it might have been helpful to include educational attainment and income inequality indicators by geographic unit because these can affect the health of both poor and wealthy individuals due to spillover effects (e.g., psychological stress) of income inequality, which can result in erosion of social cohesion [31, 32]. Additional studies should be conducted using a dataset 
Table 4 Adjusted hazard ratios of hepatocellular carcinoma mortality by sex and age groups

\begin{tabular}{|c|c|c|c|c|c|}
\hline \multirow{2}{*}{\multicolumn{2}{|c|}{$\begin{array}{ll}\text { Variables } & \\
\text { Male } & \text { Income (quintiles) }\end{array}$}} & \multirow{3}{*}{$\begin{array}{l}\text { Hazard ratio } \\
\text { Reference }\end{array}$} & \multicolumn{2}{|c|}{ 95\% Hazzard ratio confidence limits } & \multirow{2}{*}{$p$-value } \\
\hline & & & & & \\
\hline & The 5th (highest) & & & & \\
\hline & The 4th & 1.140 & 0.979 & 1.328 & 0.092 \\
\hline & The 3rd & 1.422 & 1.212 & 1.669 & $<.001$ \\
\hline & The 2nd & 1.560 & 1.325 & 1.838 & $<.001$ \\
\hline & The 1st (lowest) & 1.541 & 1.309 & 1.815 & $<.001$ \\
\hline & Trend test $^{\dagger}$ & 1.127 & 1.087 & 1.169 & $<.001$ \\
\hline \multirow[t]{7}{*}{ Female } & Income (quintiles) & & & & \\
\hline & The 5th (highest) & Reference & & & \\
\hline & The 4th & 1.033 & 0.810 & 1.318 & 0.794 \\
\hline & The 3rd & 1.107 & 0.857 & 1.429 & 0.436 \\
\hline & The 2nd & 1.129 & 0.862 & 1.477 & 0.379 \\
\hline & The 1st (lowest) & 1.265 & 0.995 & 1.607 & 0.055 \\
\hline & Trend test ${ }^{\dagger}$ & 1.057 & 1.000 & 1.118 & 0.049 \\
\hline \multirow[t]{7}{*}{ Age 49 or younger } & Income (quintiles) & & & & \\
\hline & The 5th (highest) & Reference & & & \\
\hline & The 4th & 1.270 & 0.929 & 1.735 & 0.135 \\
\hline & The 3rd & 1.595 & 1.166 & 2.181 & 0.004 \\
\hline & The 2nd & 1.714 & 1.239 & 2.371 & 0.001 \\
\hline & The 1st (lowest) & 1.568 & 1.121 & 2.193 & 0.009 \\
\hline & Trend test $^{\dagger}$ & 1.131 & 1.052 & 1.215 & 0.001 \\
\hline \multirow[t]{7}{*}{ Age 50-59 } & Income (quintiles) & & & & \\
\hline & The 5th (highest) & Reference & & & \\
\hline & The 4th & 1.509 & 1.105 & 2.059 & 0.010 \\
\hline & The 3rd & 1.593 & 1.151 & 2.204 & 0.005 \\
\hline & The 2nd & 2.089 & 1.512 & 2.887 & $<.001$ \\
\hline & The 1st (lowest) & 2.197 & 1.586 & 3.043 & $<.001$ \\
\hline & Trend test $^{\dagger}$ & 1.209 & 1.126 & 1.298 & $<.001$ \\
\hline \multirow[t]{7}{*}{ Age 60-69 } & Income (quintiles) & & & & \\
\hline & The 5th (highest) & Reference & & & \\
\hline & The 4th & 1.116 & 0.875 & 1.423 & 0.377 \\
\hline & The 3rd & 1.474 & 1.147 & 1.895 & 0.003 \\
\hline & The 2nd & 1.355 & 1.036 & 1.772 & 0.026 \\
\hline & The 1st (lowest) & 1.354 & 1.044 & 1.757 & 0.022 \\
\hline & Trend test $^{\dagger}$ & 1.087 & 1.026 & 1.150 & 0.004 \\
\hline \multirow[t]{7}{*}{ Age 70 or older } & Income (quintiles) & & & & \\
\hline & The 5th (highest) & Reference & & & \\
\hline & The 4th & 0.967 & 0.777 & 1.202 & 0.759 \\
\hline & The 3rd & 1.140 & 0.894 & 1.454 & 0.292 \\
\hline & The 2nd & 1.074 & 0.841 & 1.372 & 0.569 \\
\hline & The 1st (lowest) & 1.177 & 0.945 & 1.466 & 0.146 \\
\hline & Trend test $^{\dagger}$ & 1.042 & 0.991 & 1.096 & 0.111 \\
\hline
\end{tabular}

*All adjusted by sex, age group, disability, new cases by year, hepatitis B, hepatitis $\mathrm{C}$, alcoholic liver cirrhosis, other (non-viral, non-alcoholic) liver cirrhosis and regional level(current smoking rate, high-risk drinking rate, walking exercise practice rate, obesity rate, percentage of college graduates). ${ }^{\dagger}$ Trend test according to decrease in income level 
Table 5 Adjusted hazard ratios of hepatocellular carcinoma mortality between low- and high-income groups by sex and age groups by testing interactions

\begin{tabular}{|c|c|c|c|c|c|c|}
\hline \multicolumn{3}{|l|}{ Variable } & \multirow[t]{2}{*}{ Hazzard ratio } & \multicolumn{2}{|c|}{ 95\% Hazzard ratio confidence limits } & \multirow[t]{2}{*}{$P$-value } \\
\hline Male & Age 49 or younger & Income (quintiles) & & & & \\
\hline & & The 5th (highest) & Reference & & & \\
\hline & & The 1st (lowest) & 1.956 & 1.341 & 2.854 & $<.001$ \\
\hline & Age $50-59$ & Income (quintiles) & & & & \\
\hline & & The 5th (highest) & Reference & & & \\
\hline & & The 1st (lowest) & 2.678 & 1.827 & 3.924 & $<.001$ \\
\hline & Age 60-69 & Income (quintiles) & & & & \\
\hline & & The 5th (highest) & Reference & & & \\
\hline & & The 1st (lowest) & 1.240 & 0.913 & 1.683 & 0.169 \\
\hline & Age 70 or older & Income (quintiles) & & & & \\
\hline & & The 5th (highest) & Reference & & & \\
\hline & & The 1st (lowest) & 1.132 & 0.836 & 1.534 & 0.423 \\
\hline \multirow[t]{12}{*}{ Female } & Age 49 or younger & Income (quintiles) & & & & \\
\hline & & The 5th (highest) & Reference & & & \\
\hline & & The 1st (lowest) & 0.529 & 0.221 & 1.262 & 0.151 \\
\hline & Age $50-59$ & Income (quintiles) & & & & \\
\hline & & The 5th (highest) & Reference & & & \\
\hline & & The 1st (lowest) & 1.120 & 0.582 & 2.157 & 0.734 \\
\hline & Age 60-69 & Income (quintiles) & & & & \\
\hline & & The 5th (highest) & Reference & & & \\
\hline & & The 1st (lowest) & 1.678 & 1.007 & 2.796 & 0.047 \\
\hline & Age 70 or older & Income (quintiles) & & & & \\
\hline & & The 5th (highest) & Reference & & & \\
\hline & & The 1st (lowest) & 1.218 & 0.875 & 1.697 & 0.243 \\
\hline
\end{tabular}

*All adjusted by sex, age group, disability, new cases by year, hepatitis B, hepatitis C, alcoholic liver cirrhosis, other (non-viral, non-alcoholic) liver cirrhosis and regional level(current smoking rate, high-risk drinking rate, walking exercise practice rate, obesity rate, percentage of college graduates)

with more detailed matching of NHI claims data as well as more information on SES.

Despite these limitations, to the best of our knowledge, this is the one of only a few studies to analyze the Korean national claims dataset of $\mathrm{HCC}$ patients and to explore individual- and community-level factors associated with the survival probability of these individuals.

\section{Conclusions}

Having a low income significantly affected the overall 5year mortality of Korean adults who were newly diagnosed with HCC from 2004 to 2008. Middle-aged men were the most vulnerable. We believe our findings will be useful to healthcare policymakers in Korea as well as to healthcare leaders in countries with NHI programs who need to make important decisions about allocation of limited healthcare resources according to a consensually accepted and rational framework. Our findings also add to the mounting empirical support for development of a national cancer management strategy to narrow the gaps in, for example, survival time and access to healthcare according to demographic characteristics, including SES.

\section{Abbreviations}

HCC: Hepatocellular Carcinoma; HR: Hazard Ratio; HBV: Hepatitis B; HCV: Hepatitis C; NHI: National Health Insurance; SES: Socioeconomic Status; NHIS-NSC: Korean National Health Insurance Service-National Sampling Cohort; KCHS: Korea Community Health Survey; ICD-10: International

Classification of Diseases, Version 10; BMI: Body Mass Index; PY: Person-Years; Cl: Confidence Interval; CLD: Chronic Liver Disease; NRF: National Research Foundation of Korea

\section{Acknowledgements}

Sun Jung Kim is the guarantor of this work and, as such, had full access to all the data in the study and takes responsibility for the integrity of the data and the accuracy of the data analysis.

\section{Authors' contributions}

DJK, JWY, and Sun Jung Kim led the design and conception of the study, performed the data analysis, and wrote the manuscript. JWC, TY, ECP, KTH, and Seung Ju Kim contributed to the discussion, reviewed and edited the manuscript. The authors read and approved the final manuscript. 


\section{Funding}

This work was supported by the Soonchunhyang University Research Fund, The National Research Foundation of Korea (NRF) grant funded by the Korean government (MSIP; Ministry of Science, ICT \& Future Planning, NRF2017R1C1B5016203), and BK21 FOUR (Fostering Outstanding Universities for Research, No.: 5199990914048, Korean Ministry of Education).

\section{Availability of data and materials}

The data generated by the National Health Insurance Corporation, Republic of Korea, are not publicly available.

\section{Declarations}

\section{Ethics approval and consent to participate}

This study was reviewed and approved by the Institutional Review Board of Soonchunhyang University (2017-05-BM-014). The English in this document has been checked professional editors.

\section{Consent for publication}

Not applicable.

\section{Competing interests}

The authors declare that they have no competing interests.

\section{Author details}

'Department of Health Administration and Management, Soonchunhyang University Graduate School, Asan, Republic of Korea. ${ }^{2}$ Center for Healthcare Management Science, Soonchunhyang University, Asan, Republic of Korea. ${ }^{3}$ Department of Internal Medicine, University of Nevada Las Vegas School of Medicine, Las Vegas, Nevada, USA. ${ }^{4}$ Department of Health Administration, College of Business, Texas Women's University, Denton, TX, USA.

${ }^{5}$ Department of Sociology, Anthropology, and Health Administration and Policy, University of Maryland, Baltimore, MD, USA. ${ }^{6}$ Department of Preventive Medicine, Yonsei University College of Medicine, Seoul, Republic of Korea. ${ }^{7}$ Institute of Health Services Research, Yonsei University College of Medicine, Seoul, Republic of Korea. ${ }^{8}$ Division of Cancer Management Policy, National Cancer Center, Goyang, Republic of Korea. ${ }^{9}$ College of Nursing, Catholic University of Korea, Seoul, Republic of Korea. ${ }^{10}$ Department of Health Administration and Management, College of Medical Science, Soonchunhyang University, 22 Soonchunhyang-ro, Asan 31538, Republic of Korea. ${ }^{11}$ Department of Software Convergence, Soonchunhyang University, Asan, Republic of Korea.

Received: 26 September 2020 Accepted: 11 June 2021 Published online: 01 September 2021

\section{References}

1. Bertuccio P, Turati F, Carioli G, Rodriguez T, La Vecchia C, Malvezzi M, et al Global trends and predictions in hepatocellular carcinoma mortality. J Hepatol. 2017;67(2):302-9. https://doi.org/10.1016/j.jhep.2017.03.011.

2. Statistics Korea. Cause of death statistics in 2018. Statistics Korea. Available from: http://kostat.go.kr/portal/eng/pressReleases/8/10/index.board?bmode= read\&bSeq $=\& a S e q=378787 \&$ pageNo=1\&rowNum $=10 \&$ navCount $=$ 10\&currPg=\&searchInfo=\&sTarget=title\&sTxt=. Accessed 29 Mar 2021.

3. Kim BH, Park JW. Epidemiology of liver cancer in South Korea. Clin Mol Hepatol. 2018;24(1):1-9. https://doi.org/10.3350/cmh.2017.0112.

4. Park J, Jee $\mathrm{YH}$. Age-period-cohort analysis of liver cancer mortality in Korea. Asian Pac J Cancer Prev. 2016;16(18):8589-94. https://doi.org/10.7314/A PJCP.2015.16.18.8589.

5. Yun EH, Lim MK, Oh JK, Park JH, Shin A, Sung J, et al. Combined effect of socioeconomic status, viral hepatitis, and lifestyles on hepatocelluar carcinoma risk in Korea. Br J Cancer. 2010;103(5):741-6. https://doi.org/10.1 038/sj.bjc.6605803.

6. Artinyan A, Mailey B, Sanchez-Luege N, Khalili J, Sun CL, Bhatia S, et al. Race, ethnicity, and socioeconomic status influence the survival of patients with hepatocellular carcinoma in the United States. Interdisciplinary Int J Am Cancer Soc. 2010;116:1367-77.

7. OECD. Health at a glance 2017: OECD Indicators. OECD Publishing, Paris. Available from: https://doi.org/10.1787/health_glance-2017-en. Accessed 29 Mar 2021.
8. Kim S, Kwon S. Impact of the policy of expanding benefit coverage for cancer patients on catastrophic health expenditure across different income groups in South Korea. Soc Sci Med. 2015;138:241-7. https://doi.org/10.101 6/j.socscimed.2015.06.012.

9. Jembere N, Campitelli MA, Sherman M, Feld JJ, Lou W, Peacock S, et al. Influence of socioeconomic status on survival of hepatocellular carcinoma in the Ontario population: a population-based study, 1990-2009. PLoS One. 2012;7(7):e40917. https://doi.org/10.1371/journal.pone.0040917.

10. Andersen R, Newman JF. Societal and individual determinants of medical care utilization in the United States. The Milbank Memorial Fund quarterly. Health and Society. 1973;51:95-124.

11. Kim KO, Shin YJ. The effect of the policy of expanding coverage for four major diseases: focused on out-of-pocket payment. Health Soc Welf Rev 2017;37(2):452-76

12. Kim S, Kwon S. The effects of extension of benefit coverage for cancer patients on health care utilization across different income groups in South Korea. Int J Health Care Finance Econ. 2014;14(2):161-77. https://doi.org/10.1 007/s10754-014-9144-y.

13. Baade PD, Turrell G, Aitken JF. Geographic remoteness, area-level socioeconomic disadvantage and advanced breast cancer: a cross-sectional, multilevel study. J Epidemiol Community Health. 2011:65(11):1037-43. https://doi.org/10.1136/jech.2010.114777.

14. Dasgupta P, Baade PD, Aitken JF, Turrell G. Multilevel determinants of breast cancer survival: association with geographic remoteness and area-level socioeconomic disadvantage. Breast Cancer Res Treat. 2012;132(2):701-10. https://doi.org/10.1007/s10549-011-1899-y.

15. Baade PD, Turrell G, Aitken JF. A multilevel study of the determinants of area-level inequalities in colorectal cancer survival. BMC Cancer. 2010;10(1): $1-8$.

16. Sanderson M, Coker AL, Perez A, Du XL, Peltz G. A multilevel analysis of socioeconomic status and prostate cancer risk. Ann Epidemiol. 2006;16(12): 901-7. https://doi.org/10.1016/j.annepidem.2006.02.006.

17. Ko YS, Kim HJ, Kang YW, Kim YT. Introduction of the Korean community health Survey data. Pub Health Week Report. 2016;9:159-63 Korea Center for Disease Control and Prevention. Osong, Korea.

18. Korean Community Health Survey. Korean Center for Disease Control and Prevention. Osong, Korea. Available from: https://chs.cdc.go.kr/chs/index.do. Accessed 29 Mar 2021.

19. Korean Institute for Health and Social Affairs. Poverty Report in 2016. Research in brief. 2016-04. Sejong: Korean Institute for Health and Social Affairs; 2016.

20. Mohammed MS, Ferrier G, Abouda G, Corless L. Socio-economic deprivation significantly impact clinical management and survival in hepatocellular carcinoma. J Hepatol. 2018;68(3):623-5. https://doi.org/10.1016/j.jhep.2017. 09.031

21. Ashhab AA, Rodin H, Powell J, Debes JD. Hepatocellular carcinoma diagnosis and surveillance: socioeconomic factors don't seem to matter, unless you are an immigrant. J Hepatol. 2017;67(3):648-9. https://doi.org/1 0.1016/j.jhep.2017.05.003

22. Shebl FM, Capo-Ramos ED, Graubard BI, McGlynn KA, Altekruse SF. Socioeconomic status and hepatocellular carcinoma in the United States. Cancer Epidemiol Prev Biomarkers. 2012;21(8):1330-5. https://doi.org/10.11 58/1055-9965.EPI-12-0124.

23. Wang J, Ha J, Lopez A, Bhuket T, Liu B, Wong RJ. Medicaid and uninsured hepatocellular carinoma patients have more advanced tumor stage and are less likely to receive treatment. J Clin Gastroenterol. 2018;52(5):437-43. https://doi.org/10.1097/MCG.0000000000000859.

24. Desai AP, Mohan P, Roubal AM, Bettencourt R, Loomba R. Geographic variability in liver disease related mortality rates in the United States. Am J Med. 2018;131(7):728-34. https://doi.org/10.1016/j.amjmed.2018.01.047.

25. Hajat A, Kaufman JS, Rose KM, Siddiqui A, Thomas JC. Long-term effects of wealth on mortality and self-rated health status. Am J Epidemiol. 2011; 173(2):192-200. https://doi.org/10.1093/aje/kwq348.

26. Keene DE, Cowan SK, Baker AC. "When you're in a crisis like that, you don't want people to know": mortgage strain, stigma, and mental health. Am J Public Health. 2015;105(5):1008-12. https://doi.org/10.2105/AJPH.2014.3024 00

27. Pool LR, Burgard SA, Needham BL, Elliott MR, Langa KM, De Leon CFM. Association of a negative wealth shock with all-cause mortality in middleaged and older adults in the United States. JAMA. 2018:319(13):1341-50. https://doi.org/10.1001/jama.2018.2055. 
28. Kim D. The associations between US state and local social spending, income inequality, and individual all-cause and cause-specific mortality: the National Longitudinal Mortality Study. Prev Med. 2016;84:62-8. https://doi. org/10.1016/j.ypmed.2015.11.013.

29. Park SA, Choi Y. Sustained impact of sustained economic hardship on health behaviors and health outcomes: A marginal structural model. 8th annual conference of Korea Health Panel. Session 1-2: Health equality. Pp. 171-191. December 2016. Seoul, Korea. Korea Institute for Health and Social Affairs.

30. Petrovic D, de Mestral C, Bochud M, Bartley M, Kivimäki M, Vineis P. The contribution of health behaviors to socioeconomic inequalities in health: a systematic review. Prev Med. 2018;113:15-31. https://doi.org/10.1016/j. ypmed.2018.05.003.

31. Kawachi I, Subramanian SV. Chapter 4. Income inequality. Pp.126-152. In: Berkman LF, Kawachi I, Glymour MM, editors. Social Epidemiology. 2nd ed. New York: Oxford University Press; 2014.

32. Kondo N, Sembajwe G, Kawachi I, van Dam RM, Subramanian SV, Yamagata Z. Income inequality, mortality, and self-rated health: meta-analysis of multilevel studies. BMJ. 2009;339(nov10 2):b4471. https://doi.org/10.1136/ bmj.b4471.

\section{Publisher's Note}

Springer Nature remains neutral with regard to jurisdictional claims in published maps and institutional affiliations.

- fast, convenient online submission

- thorough peer review by experienced researchers in your field

- rapid publication on acceptance

- support for research data, including large and complex data types

- gold Open Access which fosters wider collaboration and increased citations

- maximum visibility for your research: over $100 \mathrm{M}$ website views per year

At $\mathrm{BMC}$, research is always in progress.

Learn more biomedcentral.com/submissions 